\title{
UNIVERSITYOF
}

FORWARD

THINKING

WESTMINSTER用

WestminsterResearch

http://www.westminster.ac.uk/westminsterresearch

\section{Natural outdoor environment, neighbourhood social cohesion and mental health: Using multilevel structural equation modelling, streetscape and remote-sensing metrics Yuqi Liu, Ruoyu Wang, Yi Lu, Zhigang Li, Hongsheng Chen, Cao, M., Yuerong Zhang and Yimeng Song}

NOTICE: this is the authors' version of a work that was accepted for publication in Urban Forestry \& Urban Greening. Changes resulting from the publishing process, such as peer review, editing, corrections, structural formatting, and other quality control mechanisms may not be reflected in this document. Changes may have been made to this work since it was submitted for publication. A definitive version was subsequently published in Urban Forestry \& Urban Greening, DOI: 10.1016/j.ufug.2019.126576, 2020.

The final definitive version in Urban Forestry \& Urban Greening is available online at: https://dx.doi.org/10.1016/j.ufug.2019.126576

(C) 2020. This manuscript version is made available under the CC-BY-NC-ND 4.0 license https://creativecommons.org/licenses/by-nc-nd/4.0/

\footnotetext{
The WestminsterResearch online digital archive at the University of Westminster aims to make the research output of the University available to a wider audience. Copyright and Moral Rights remain with the authors and/or copyright owners.
}

Whilst further distribution of specific materials from within this archive is forbidden, you may freely distribute the URL of WestminsterResearch: ((http://westminsterresearch.wmin.ac.uk/)).

In case of abuse or copyright appearing without permission e-mail repository@westminster.ac.uk 



\section{Journal Pre-proof}

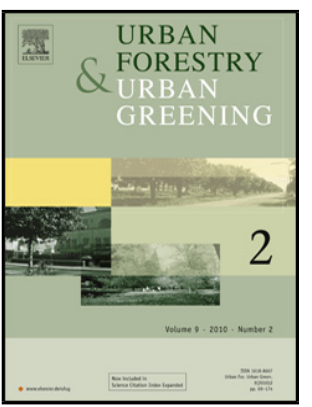

Yuqi Liu, Ruoyu Wang, Yi Lu, Zhigang Li, Hongsheng Chen, Mengqiu Cao, Yuerong Zhang, Yimeng Song

\begin{tabular}{|c|c|}
\hline PII: & S1618-8667(19)30521-7 \\
\hline DOI: & https://doi.org/10.1016/j.ufug.2019.126576 \\
\hline Reference: & UFUG 126576 \\
\hline To appear in: & Urban Forestry \& Urban Greening \\
\hline Received Date: & 9 July 2019 \\
\hline Revised Date: & 28 December 2019 \\
\hline Accepted Date: & 30 December 2019 \\
\hline
\end{tabular}

Please cite this article as: Liu Y, Wang R, Lu Y, Li Z, Chen H, Cao M, Zhang Y, Song Y, Natural outdoor environment, neighbourhood social cohesion and mental health: Using multilevel structural equation modelling, streetscape and remote-sensing metrics, Urban Forestry and amp; Urban Greening (2020), doi: https://doi.org/10.1016/j.ufug.2019.126576

This is a PDF file of an article that has undergone enhancements after acceptance, such as the addition of a cover page and metadata, and formatting for readability, but it is not yet the definitive version of record. This version will undergo additional copyediting, typesetting and review before it is published in its final form, but we are providing this version to give early visibility of the article. Please note that, during the production process, errors may be discovered which could affect the content, and all legal disclaimers that apply to the journal pertain.

(C) 2019 Published by Elsevier. 


\section{Natural outdoor environment, neighbourhood social cohesion and mental health: Using multilevel structural equation modelling, streetscape and remote- sensing metrics}

Yuqi Liu, Ruoyu Wang*, Yi Lu, Zhigang Li*, Hongsheng Chen, Mengqiu Cao, Yuerong Zhang, Yimeng Song

Yuqi Liu

Department of Urban Planning and Design, The University of Hong Kong, Pokfulam Road, Hong Kong; Email: yuqiliu6@hku.hk

Ruoyu Wang * (Corresponding author)

Institute of Geography, School of GeoSciences, University of Edinburgh, Edinburgh, UK; Email: R.Wang-54@sms.ed.ac.uk

Yi Lu $\mathrm{Lu}^{\mathrm{a} b}$

a. Department of Architecture and Civil Engineering, City University of Hong Kong, Hong Kong;

b. City University of Hong Kong Shenzhen Research Institute, Shenzhen, China

Email: yilu24@cityu.edu.hk

Zhigang Li** (Corresponding author)

Department of Urban and Rural Planning, School of Urban Design, Wuhan University, Wuhan, Hubei Province, China; Email: zhigangli@whu.edu.cn

Hongsheng Chen

Architecture School, Southeast University, Nanjing, Jiangsu, China; 
Email: chen.hongsheng@seu.edu.cn

Mengqiu $\mathrm{Cao}^{\mathrm{a}, \mathrm{b}}$

a. School of Architecture and Cities, University of Westminster, London NW1 5LS, UK;

b. Bartlett School of Planning, University College London, London WC1H 0NN, UK; Email: m.cao@westminster.ac.uk; mengqiu.cao.13@ucl.ac.uk

Yuerong Zhang ${ }^{\mathrm{a}, \mathrm{b}}$

a. Bartlett School of Planning, University College London, Gower Street, London WC1H 0NN, UK

b. Centre for Advance Spatial Analysis, University College London, Gower Street, London WC1E 6BT, UK; Email: yuerong.zhang.14@ucl.ac.uk

Yimeng Song

Department of Geography and Resource Management, The Chinese University of Hong Kong, Shatin, Hong Kong; Email: yimengsong@link.cuhk.edu.hk

\section{Highlights}

- Street view(SV) greenness influenced mental health directly by its visual effect.

- SV greenness affected mental health indirectly through attachment and community participation.

- SV blueness influenced mental health in a direct manner only.

- Surrounding green and blue space were positively and directly associated with 
mental health.

\begin{abstract}
Although a growing body of research has explored the relationship between neighbourhood natural outdoor environments and mental health, most studies have measured neighbourhood natural outdoor environments from a bird's-eye perspective, rather than measuring the visual experience of green and blue space that individuals have at the ground level. In addition, few studies have investigated how different dimensions of neighbourhood social cohesion mediates the relationship between the natural outdoor environment and mental health. To bridge these gaps, we examined the relationship between neighbourhood natural outdoor environments and individuals' mental health in Guangzhou, China, using a combination of questionnaire survey data, streetscape and remotesensing metrics, and multilevel structural equation modelling. More particularly, this study explored the mediating effects of three dimensions of neighbourhood social cohesion (i.e. neighbourhood attachment, neighbourly interaction, and community participation). The results indicate that neighbourhood green space and blue space are both positively associated with individuals' mental health. Neighbourhood street greenery exerts beneficial effects on mental health, directly by its visual effect, and indirectly by improving neighbourhood attachment and community participation. Neighbourhood street-view blue space and surrounding green (blue) space also has a positive influence on mental health, but it does so in a direct manner only. This study contributes to our knowledge by estimating the mediating impacts of three dimensions of neighbourhood social cohesion and applying both streetscape and remote-sensing metrics of visible green space and blue space within neighbourhoods.
\end{abstract}

Keywords: Neighbourhood green space and blue space, Mental wellbeing, Neighbourhood social cohesion, Streetscape metric, Remote-sensing metric, Multilevel structural equation models 


\section{Introduction}

A natural environment is beneficial to the health and well-being of urban dwellers. The beneficial effects of such environments have long been recognised and applied in the fields of urban planning and public health, dating back to the first practice of building public parks in England in the 19th century (Barton et al., 2015). More recently, a number of guidelines have been issued by international health organisations that emphasise the significant benefits of neighbourhood natural outdoor environments for individuals' physical and mental health (WHO, 2016, WHO, 2017). For example, the World Health Organisation (WHO, 2010) suggested that physical activity in neighbourhood natural outdoor environments can help to reduce depression and stress. Such environments invite local people to expose themselves to green spaces and exercise more regularly.

Many empirical studies have shown that exposure to neighbourhood natural outdoor environments, such as green and blue spaces, positively influences people's mental health (Hartig et al., 2014, van den Berg et al., 2017, de Bell et al., 2017, Dzhambov et al., 2018). Furthermore, scholars have proposed several pathways to explain the relationship between exposure to neighbourhood natural outdoor environments and mental health. These pathways include mitigating exposure to environmental stressors, restoring attention, facilitating recovery from stress, encouraging physical activity and facilitating social cohesion (Hartig et al., 2014, de Bell et al., 2017, Markevych et al., 2017, Haeffner et al., 2017). Most of these pathways have been widely tested, including the mitigation of exposure to stressors (Hartig et al., 2014, Markevych et al., 2017, de Vries et al., 2013), restoration of attention (Ulrich et al., 1991, van den Berg et al., 2010, Thompson et al., 2012), facilitation of recovery from stress (Hartig et al., 1991) and encouragement of physical activities (Bauman et al., 2012, Liu et al., 2017a). Nevertheless, little research has been done to investigate the pathway of facilitation for social cohesion (Maas et al., 2009, de Bell et al., 2017). Such research has been especially lacking in the context of cities in developing countries, which are commonly characterised by rapid urbanisation and high population densities.

To date, empirical evidence has been inconclusive concerning the positive relationship between 
neighbourhood natural outdoor environments and mental health. Several studies have reported no statistically significant association (Alcock et al., 2015, Boers et al., 2018, Gascon et al., 2017). An important reason for these inconclusive findings may be that existing measures of neighbourhood green and blue spaces are unable to capture the actual degrees of exposure that individuals have to such spaces. The most widely used measures are derived from remote sensing images. These images are based on indicators of vegetation and water (McFeeters, 1996) and the classification of images into land use categories (Helbich et al., 2018). Such remotely sensed measures of urban green cover and water cover are unable to accurately assess individuals' daily exposure to natural environments (Lu, 2018, Ye et al., 2018). For one thing, the low resolution of remote sensing data (e.g., 50 meters) may lead to biased estimations of indicators (Yang et al., 2003). For instance, small-scale green spaces within neighbourhoods cannot be accurately captured and classified into proper land use categories by low-resolution remote sense images. In addition, satellite images reveal a bird's eye perspective, rather than the ground-level visual perspective that individuals actually have on the green and blue spaces around them (Helbich et al., 2018, Ye et al., 2018).

To overcome these constraints, this study used streetscape images and remote-sensing metrics to examine the relationship between neighbourhood natural outdoor environments and individuals' mental health in Guangzhou, China, a city characterised by rapid urbanisation, a large migrant population and a high population density. This study has two major contributions. First, we measured the eye-level exposure to green and blue spaces within neighbourhoods, as grounded in street view images and deep learning techniques. Second, we developed a questionnaire to capture the multi-dimensional nature of neighbourhood social cohesion (i.e., neighbourhood attachment, neighbourly interaction, and community participation). Unlike earlier measures, which have only assessed neighbourhood social cohesion in one dimension. In this study, we focused on how three different dimensions of neighbourhood social cohesion mediate the association of neighbourhood natural outdoor environments and mental health.

\section{Literature review}




\subsection{Neighbourhood natural outdoor environment exposure and mental health}

'Mental health' refers to a state of well-being in which individuals can effectively utilise their own ability to work productively, deal with the stress of daily life and contribute to their own communities (Kawachi and Berkman, 2001). Diminished mental health is a significant precursor of a range of chronic physical and mental diseases. Levels of mental health have been commonly measured by several classical scales, including the General Health Questionnaire (GHQ-12) (Goldberg and Hillier, 1979), the Short Warwick Edinburgh Mental Well-being Scale (Tennant et al., 2007) and the EQ-5D questionnaire (Group, 1990). In addition to being influenced by biological factors, mental health is also affected by the characteristics of residential environments, such as population density and land use diversity (Patel et al., 2007, Sugiyama et al., 2008, Gale et al., 2011). Neighbourhood natural outdoor environments, especially green spaces and blue spaces, have been found to significantly contribute to individuals' mental health (Laumann et al., 2003, Nielsen and Hansen, 2007, Karmanov and Hamel, 2008, Hartig et al., 2014, Nutsford et al., 2016, van den Berg et al., 2017, Dzhambov et al., 2018, de Keijzer et al., 2019).

When studying the positive association between neighbourhood green space and mental health, researchers have mainly focused on the accessibility and quality of green space. Scholars have applied various measurements of green space availability (Markevych et al., 2017), including the widely used measure of the green space coverage rate in buffer areas surrounding people's homes (e.g., a 1 km circular network buffer) (Maas et al., 2009, Beyer et al., 2014, Astell-Burt et al., 2014). Other measures of green and blue space include the euclidean distance to the nearest green space (Nutsford et al., 2009) and the subjective presence of green space within a given distance (Sugiyama et al., 2008). As has been demonstrated in several studies, residents with convenient access to green space commonly report a lower incidence of psychological disorders and mental illnesses (Nielsen and Hansen, 2007, Astell-Burt et al., 2014, Hartig et al., 2014, van den Berg et al., 2017, Dzhambov et al., 2018). Furthermore, the quality of green space may also play an important role in maintaining mental health. One study reported that the quality rather than the quantity of neighbourhood green spaces was significantly associated with mental health among residents in Perth, Australia (Francis 
et al., 2012).

Exposure to neighbourhood blue space also has significant emotional effects and direct health benefits. Visible waterscapes in neighbourhoods serve as therapeutic spaces that can reduce distress by serving as peaceful backdrops to everyday life (Laumann et al., 2003, Pretty et al., 2005, Karmanov and Hamel, 2008). Comparing two groups of participants, Laumann et al. (2003) found a higher level of attentiveness in participants who viewed a costal environment video than in those who viewed an urban environment video. Karmanov and Hamel (2008) conducted a study in urban neighbourhoods of the Netherlands, and found that visible blue space served to reduce stress and enhance positive moods. Pretty et al. (2005) suggested that the proximity to blue space contributes to physical activities, which reduce blood pressure and anxiety. However, these health impacts of blue space remain unconfirmed, as some empirical studies have found no significant associations between blue space and physical or mental health (Foley and Kistemann, 2015, Nutsford et al., 2016, Gascon et al., 2017, Dempsey et al., 2018).

2.2 The mediating impact of neighbourhood social cohesion on the relationship between neighbourhood natural outdoor environment and mental health

Existing studies have proposed several potential pathways for the mechanisms by which neighbourhood natural outdoor environments may influence mental health (Markevych et al., 2017). We have identified three such pathways of influence from the existing literature. First, as a restorative environment, neighbourhood natural outdoor environment offers individuals opportunities to view plants and waterscapes, and generates positive emotions and feelings of being away from everyday life in individuals (Hartig et al., 2014, Nowak et al., 2014, Wang et al., 2019c). Natural environment helps residents to overcome negative thoughts and emotions, thereby greatly improves residents' capacity to deal with stress. Second, neighbourhood natural outdoor environments offer attractive settings that encourage physical activity, which in turn has great psychological and physiological benefits (Astell-Burt et al., 2014). Third, we suggest that 
cultivating neighbourhood social cohesion is another mechanism through which green and blue space affects individuals’ mental health (Maas et al., 2009, de Vries et al., 2013).

Social cohesion has been defined in several ways (Forrest and Kearns, 2001, Friedkin,2004, Kearns and Forrest, 2000). Existing definitions consistently allude to territorial belonging, social networks, common values and civic participation. To provide conceptual clarity, scholars have divided neighbourhood social cohesion into three components, including neighbourhood attachment, neighbourly interaction, and community participation (Forrest and Kearns, 2001). Each component may influence mental health in different ways. Through the daily use of natural outdoor spaces, individuals foster neighbourhood attachment, and thereby benefit from its relaxation effect (i.e. place-as-relaxation) and achieve restoration from depleted emotional states (Scannell and Gifford, 2010, Lewicka, 2011, Scannell and Gifford, 2017). Neighbourhood natural outdoor areas also provide settings for individuals to meet and interact, through which individuals can escape from daily stressors or seek help from neighbours (Forrest and Kearns, 2001, Sugiyama et al., 2008, Maas et al., 2009, Peters et al., 2010). For example, individuals actively interacting with neighbours often feel they can exchange information and find support in dealing with mental health problems (Kawachi et al., 1999, Berkman et al., 2000). Community participation provides feelings of being valued and respected, and thereby has a positive effect on mental health (Greiner, et al., 2004, Berry et al., 2007, Ding et al., 2015). For instance, Ding et al. (2015) found that a higher level of past community participation was associated with better mental health next year based on a panel analysis of Australia. Therefore, individuals residing in socially cohesive neighbourhoods can better cope with the stress of daily life, and they tend to report higher levels of mental health.

In the past, most empirical studies on this topic have focused on examining only the first two mechanisms (positive emotions and physical activity) (Hartig et al., 2014, Nowak et al., 2014, Astell-Burt et al., 2014), neglecting the third mechanism (social cohesion). The handful of studies that have considered the mechanism of neighbourhood social cohesion have generated mixed results. Some scholars have indicated that social interaction mediated the positive relationship between 
green space and mental health (Maas et al., 2009, de Vries et al., 2013). However, other researchers have argued that neighbourhood social interaction is unlikely to serve as a mediating factor (Triguero-Mas et al., 2015). This divergence in findings might be caused by different methods to measure social cohesion (Maas et al., 2009). As a multidimensional concept, neighbourhood social cohesion involves a range of aspects, including neighbourhood attachment, neighbourly interaction, and community participation (Forrest and Kearns, 2001). Therefore, it is of great importance to test the three dimensions of neighbourhood social cohesion respectively when examining its impacts on mental health.

\subsection{Research in a Chinese context}

To date, only a handful of studies have explored the relationship between exposure to neighbourhood natural outdoor environments and individual health outcomes in urban China (Su et al., 2016, Jia et al., 2018, Lu, 2018, Helbich et al., 2019, Liu et al., 2019a, Liu et al., 2019b). The majority of the existing studies conducted in Chinese cities have estimated only the relationship between neighbourhood green space and individual health outcomes (Su et al., 2016, Jia et al., 2018). For instance, Jia et al. (2018) collected survey data in communities of Bengbu, Anhui Province, and they identified a mediating role of physical exercise in the relationship between exposure to neighbourhood green space and the risk of cardiovascular diseases among elderly residents. However, few academic studies have examined the effects of neighbourhood blue space on mental health in China, or the mediating effects of neighbourhood social cohesion.

Several empirical studies in China have indicated that residential green space has a protective effect on individuals' health in high-density cities (Liu et al., 2017a, Ma et al., 2017, Xiao et al., 2017). In addition, residential green space has been found to be positively associated with residents' participation in physical activities, interaction with neighbours and emotional attachment to neighbourhoods (Lu, 2018, Liu et al., 2017a, , Liu et al., 2017b, Liu et al., 2019c, Zhu and Fu, 2017, Wu and Dong, 2013). Therefore, we hypothesise that green space within a neighbourhood is 
associated with better mental health (Hypothesis 1). Moreover, we propose a second hypothesis that neighbourhood blue space is positively related to individuals' mental health (Hypothesis 2). Finally, we propose that the three dimensions of social cohesion mediates the relationship between a neighbourhood's natural outdoor environment and residents' mental health (Hypothesis 3).

$* * * * * * * * * * * * * * * * * * * * * * * * * * * * *$ Insert Figure 1 here $* * * * * * * * * * * * * * * * * * * * * * * * * * * * * * * * * *$

\section{Data and methods}

\subsection{Study area and population}

The main data in this study were collected from a questionnaire survey carried out in Guangzhou from June to August 2015. The survey team selected the sampled respondents through a multi-stage, stratified sampling technique that was probability-proportionate to population size. First, we randomly chose 23 residential neighbourhoods (she qu) from 7 inner-city and inner-suburb area districts (Huangpu, Yuexiu, Haizhu, Panyu, Baiyun, Tianhe and Liwan) in Guangzhou, China (Figure 2). Second, we randomly selected 50 households from each sampled neighbourhood using the systematic sampling method, and then chose one member of each household using the Kish grid method. Finally, the survey generated 1,150 valid respondents in total.

$* * * * * * * * * * * * * * * * * * * * * * * * * * * * *$ Insert Figure 2 here $* * * * * * * * * * * * * * * * * * * * * * * * * * * * * * * * * * *$

\subsection{Measurement of variables}

\subsubsection{Mental health}

In our Guangzhou questionnaire survey, mental health was measured by the 12-item version of the 
GHQ-12. The respondents were asked to rate how often they had experienced mental problems, such as feelings of nervousness, unhappiness, or depression, over the previous week (Chan, 1985, Li et al., 2007). A 4-point Likert-type scale ranging from 1 (never) to 4 (always) was used for each item. The total score for these items ranged from 12 to 48 . The positive items were corrected from 1 (always) to 4 (never), and the negative items were corrected from 4 (always) to 1 (never). Therefore, a higher total score suggested a worse mental health status. Cronbach's alpha for the total score in the GHQ-12 was 0.82 for the entire sample, which indicated satisfactory internal consistency. The overall GHQ-12 score was treated as a continuous variable (Hauck and Rice, 2004, Netuveli et al., 2008).

\subsubsection{Neighbourhood natural outdoor environment}

\section{Capturing neighbourhood street view greenness and blueness using street view data}

The neighbourhood natural outdoor environment was measured by indicators of street view greenness and blueness. In this study, 'green space' refers to areas of grass and trees in the images, and 'blue space' refers to rivers and lakes. We measured street view greenness and blueness for each sampled neighbourhood using a large number of street view images collected in 2015. These images were obtained from Tencent Maps, which is the equivalent of Google Maps in China (Tencent Maps, 2015). This mapping application has the most comprehensive street view service database, with the largest image coverage (Long and Liu, 2017), and it offers rich information on the actual scenery from various positions. Building on the OpenStreetMap project (Arsanjani et al., 2015), we created sampling points along the road network at 100 meter intervals, and the street view pictures were retrieved through the Tencent street view application programming interface. To simulate a $360^{\circ}$ view that surrounds a person at each sampled point, we downloaded four street view images, one for each of the four main cardinal directions (i.e., $0^{\circ}, 90^{\circ}, 180^{\circ}$ and $270^{\circ}$ ) (Helbich et al., 2019, Wang et al., 2019a, Wang et al., 2019b). The size of each image was $480 \times 320$ pixels, and 125,656 street view images were obtained from the study area. 
A machine learning approach was applied to derive the indicators of street view greenness and blueness from the street view images. We applied a semantic segmentation technique, which is superior to the traditional colour-based classification method (i.e., the RGB approach). This segmentation technique was able to accurately distinguish natural water bodies and green plants from manmade blue and green objects in the street view images (Helbich et al., 2019). The deep learning method is an effective means of identifying objects in pictures (LeCun et al., 2015). Therefore, we applied a fully convolutional neural network for semantic segmentation (FCN-8s) (Long et al., 2015) to segment the street view images into different objects (e.g., trees, grasses, rivers and lakes).

The FCN-8s model provides a highly efficient convolutional neural network for semantic segmentation, and it has been widely used in previous studies. Figure 3 explains the workflow. To train our own FCN-8s, we used ADE20K data (Zhou et al., 2017, Zhou et al., 2019). This system had already labelled a large number of images (more than 150 ground objects). The accuracy of the training images was 0.814 , and the accuracy of the test images was 0.802 . The ratio of street-level green space (blue space) for each sampling point was determined as the ratio of the number of green space (blue space) pixels per image summed over the four cardinal directions to the total number of pixels per image summed over the four cardinal directions. We calculated street view green space/blue space within a circular buffer of 1,500 meters around the geocoded address of the central point for each sampled neighbourhood. To obtain a neighbourhood-based street-level green space (blue space) measure, we averaged the image-specific green space (blue space) scores for each area.

$* * * * * * * * * * * * * * * * * * * * * * * * * * * * *$ Insert Figure 3 here $* * * * * * * * * * * * * * * * * * * * * * * * * * * * * * * * * *$

\section{Measuring the surrounding amount of green space and blue space using land cover data}

We also measured the surrounding green space and blue space within the 1,500 meter buffer area 
based on remote-sensing data from the GlobeLand30 dataset (Jun et al., 2014). This dataset was developed by the National Geomatics Center of China, with 30 meters spatial resolution. Green space consisted of cultivated land, forest, and grassland, while surrounding blue space consisted of river, lake, reservoir, fish pond, and other types of water bodies.

\subsubsection{Neighbourhood social cohesion}

Social cohesion was measured in three dimensions, including neighbourhood attachment, neighbourly interaction and community participation (see Table 1). Indicator 1 to 7 measured the level of neighbourhood attachment, and these indicators were adapted from the sense of community index developed by McMillan and Chavis (1986). The result of Cronbach's alpha for neighbourhood attachment indicators was 0.836. Indicator 8 and 9 measured respondents' neighbourhood interaction which were adapted from Völker et al. (2007). The Cronbach's alpha for neighbourly interaction indicators was 0.748 . Indicator 10 to 15 measured respondents' community participation. These indicators were adapted from Mass et al. (2009). The Cronbach's alpha for community participation was 0.758 . We calculated a total score for each dimension respectively. Three variables measuring different dimensions of social cohesion were added in the structural equation models.

**********************************) Insert Table 1 here $* * * * * * * * * * * * * * * * * * * * * * * * * * * * * * * * * *$

\subsubsection{Controlled variables}

The regression results were adjusted for the following individual-level controlled variables: gender, age, educational attainment, marital status, hukou status, employment status, participation in medical insurance and average household income per household member. The summary statistics of the variables included in our regressions are shown in Table 2. 
*************************************) Insert Table 2 here $* * * * * * * * * * * * * * * * * * * * * * * * * * * * * * * * *$

\subsection{Multilevel structural equation model (Multilevel SEMs)}

In this study, we regarded individuals' mental health as a function of the neighbourhood natural outdoor environment, neighbourhood social cohesion and the respondents' socioeconomic and demographic characteristics. As the variation in mental health can be classified to individual- and neighbourhood-level variations, we used multilevel SEMs (Raudenbush and Bryk., 2002, Gelman and Hill, 2006, Enders and Tofighi, 2007). Multilevel SEMs are superior to single-level SEMs, because they can generate correct inferences by taking into account both the individual-level and neighbourhood-level residuals. Therefore, the 1,150 sampled respondents at level 1 were nested within 23 neighbourhoods at level 2 . The statistical analysis was conducted in the software program of STATA 14.0.

We proceeded the analysis through three steps. First, we regressed the GHQ-12 scores (i.e., the dependent variable) on the natural outdoor environment indicators (i.e., street view greenness and blueness, and surrounding amount of green space and blue space), three hypothesised mediators (i.e. neighbourhood attachment, neighbourly interaction, community participation) and the controlled variables (Table 1 and 2). Second, we examined the direct and indirect effects of the street view greenness and blueness on the GHQ-12 score with the three mediators simultaneously. Third, we conducted sensitivity check to test the robustness of the results. Goodness-of-fit was assessed by standardized root mean square residual (SRMSR), root mean square error of approximation (RMSEA), and comparative fit index (CFI). Hu and Bentler (1999) suggested that the acceptable model fit should be as follows: RMSEA $(\leqslant 0.06,90 \% \mathrm{CI} \leqslant 0.06)$, SRMSR $(\leqslant 0.08)$, and CFI $(\geqslant$ 0.90). The software program of STATA 14.0 only provided the goodness-of-fit for single-level SEMs, so we calculated the above goodness-of-fit based on the approach proposed by Ryu and West 
(2009). This approach only requires the chi-square values and degrees of freedom for hypothesized model and the null model. The goodness-of-fit for single-level SEMs was also provided as a reference.

\section{Results}

\subsection{Characteristics of sampled neighbourhoods and respondents}

Table 1 indicates the descriptive statistics of all variables. The average score of GHQ-12 was 22.634 ( $\mathrm{SD} \pm 5.267)$, far below the cut-off point (i.e. $2 / 3$ of the overall score 48 ), which revealed that Guangzhou residents had good mental health. On average, the interquartile ranges of neighbourhood street view greenness and blueness were 0.235 ( $\mathrm{SD} \pm 0.081)$ and 0.004 ( $\mathrm{SD} \pm 0.003)$. The average area of neighbourhood surrounding green space and blue space were $0.191 \mathrm{~m}^{2}(\mathrm{SD} \pm 0.243)$ and $0.058 \mathrm{~m}^{2}$ ( $\mathrm{SD} \pm 0.081)$. For neighbourhood social cohesion, the average level of neighbourhood attachment, neighbourly interaction, and community participation were 26.205 (SD \pm 3.992$), 6.113$ (SD \pm 1.649 ), and $12.166(\mathrm{SD} \pm 4.041)$, respectively. As for individual characteristics, the average age of respondents was 39.553 years old. More than two third of them attained high school or below education $(65.304 \%)$, participated in medical insurance $(86.522 \%)$, and got married $(80 \%)$ and employed (83.913\%). The average annual household income per household member was $46,251.866 \mathrm{CNY}$.

\subsection{Multilevel structural equation models}

We analysed the association between street view greenness (blueness) and mental health (Table 3 and Table 5). We then estimated the correlation between surrounding amount of both green space (blue space) and mental health (Table 4 and Table 5). Besides, results indicating the mediating role of different dimensions of neighbourhood social cohesion were shown in Table 5. Finally, we conducted sensitivity checks to test the robustness of the results. The comparative fixed indexes (CFI) of both Model 1 and Model 2 were all $>0.90$, and the root mean square error of approximation 
(RMSEA) are $<0.05$, indicating good model fitness.

\subsubsection{Association between neighbourhood natural outdoor environment and mental health}

As expected, the findings indicated that neighbourhood street view greenness and blueness had beneficial effects on individuals' mental health. Models 1 showed that the rates of both street view greenness and blueness had negative a direct effect on individual residents' rates of mental illness (see Table 3). One percent increases in the rates of neighbourhood street view greenness and blueness led to decreases of 0.900 (for greenness) and 0.406 (for blueness) in the GHQ-12 scores. The respondents who were exposed to more street greenery and blue space in their surrounding neighbourhood environments had significantly lower GHQ-12 scores than the respondents residing in neighbourhoods with lower percentage of street greenery and blue space. We then estimated the association between surrounding amount of natural environment and mental health. In Model 2 (Table 4), GlobeLand30 greenness and blueness showed a negative direct effect on the GHQ-12 scores respectively $(-2.369, p<0.05 ;-5.348, p<0.1)$, after controlling for neighbourhood social cohesion, demographic characteristics, and socioeconomic status. Given that the GHQ-12 score represents the severity of an individual's mental illness, these findings verify our Hypothesis 1 and Hypothesis 2, showing that both neighbourhood street greenness (blueness) and surrounding amount of green space (blue space) are positively associated with individuals' mental health. No controlled variables were significantly related to the severity of individuals' mental problems except education attainment and employment status. The sampled respondents who were employed and well educated displayed less mental illness than those who were unemployed or less well educated.

\subsubsection{The mediating effect from the three dimensions of neighbourhood social cohesion on}

\section{neighbourhood green space and mental health}

To examine the mediating effect of neighbourhood social cohesion on the relationship between neighbourhood green space and mental health, we also added the three dimensions of 
neighbourhood social cohesion simultaneously in Model 1(Table 3). Neighbourhood street view greenness was found to be significantly and positively related to both neighbourhood attachment and community participation. A one percent increase in the neighbourhood street view greenness rate increased the score of neighbourhood attachment and that of community participation by 0.741 and 0.185 , respectively. For surrounding amount green space (Model 2), GlobeLand30 greenness indicated positive association with neighbourly interaction $(0.903, p<0.01)$. In addition, a number of controlled variables were associated with the three dimensions of neighbourhood social cohesion. Respondents with a local hukou status and local medical insurance were more likely to experience a higher level of neighbourhood attachment and neighbourly interaction, and participated actively in community activities than the other respondents. Besides, we found that respondents earning a higher household income tended to interact less with neighbours and participate less in community activities and affairs.

Model 1 and 2 showed that both neighbourhood attachment $(-0.214, p<0.01 ;-0.229, p<0.01)$ and community participation $(-0.165, p<0.01 ;-0.166, p<0.01)$ were negatively associated with the GHQ-12 scores. These findings suggested that individuals with strong attachment to neighbourhood and actively participation in community activities tend to had better mental health. Findings from Table 5 confirmed that street view greenness influenced GHQ-12 score through more paths than GlobeLand 30 greenness. The relationship between street view greenness and GHQ-12 score was significantly mediated by neighbourhood attachment $(-0.153, p<0.01)$ and community participation $(-0.031, p<0.01)$. Therefore, this finding partly confirmed our Hypothesis 3: that exposure to neighbourhood street-level greenery strengthens neighbourhood social cohesion, which is negatively associated with individuals' mental illness.

\subsubsection{The mediating effect from the three dimensions of neighbourhood social cohesion on}

\section{neighbourhood blue space and mental health}

Models 1 and 2 explored the mediating role of different dimensions of neighbourhood social 
cohesion in the relationship between neighbourhood blue space and mental health. Unexpectedly, there was no statistical evidence from Model 1 to support a significant association between neighbourhood street view blueness and neighbourhood social cohesion. For surrounding amount of blue space, GlobeLand 30 blueness only had positive association with neighbourly interaction $(1.434, p<0.05)$. However, the results of Table 5 revealed that there were no significant mediation effects of the three dimensions of neighbourhood social cohesion. Therefore, neighbourhood social cohesion was not found to mediate the observed relationship between neighbourhood blue space (both surrounding blue space and street view blueness) and individuals' mental health. These findings partly rejected our Hypothesis 3.

*****************************Insert Tables 3, 4 and 5 here*******************************

\subsection{Sensitivity check}

The results of sensitivity check are shown in Table 7 and 6 . The street view greenness (blueness) and GlobeLand 30 greenness (blueness) of $1500 \mathrm{~m}$ buffer area were replaced by that of $1000 \mathrm{~m}$ buffer area. It is apparent that the correlation patterns (shown in Model 3 and 4) among street view greenness (blueness), GlobeLand 30 greenness (blueness), neighbourhood social cohesion, and mental health are consistent with those shown in Model 1 and 2.

$* * * * * * * * * * * * * * * * * * * * * * * * * * * * *$ Insert Tables 6 and 7 here $* * * * * * * * * * * * * * * * * * * * * * * * * * * * * *$

\section{Discussion}

\subsection{Main findings}

The objective of this study was to examine the relationship between neighbourhood natural outdoor 
environments and individuals' mental health in Chinese cities. To determine this relationship, we used streetscape metric, remote-sensing metric, and multilevel structural equation modelling techniques with a particular focus on the mediating role of neighbourhood social cohesion. The results indicated that both neighbourhood street view greenness (blueness) and surrounding green space (blue space) were directly and positively associated with individuals' mental health. The results of our mediation analysis revealed that the exposure to neighbourhood street view greenness (but not blueness) positively affected individuals' mental health through the pathway of neighbourhood attachment and community participation.

\subsection{The direct effects of neighbourhood natural outdoor environment on mental health}

Previous researchers have recognised an urgent need to go beyond simply measuring the quantity of neighbourhood natural outdoor environments from a bird's-eye perspective (Lu, 2018, Ye et al., 2018, Helbich et al., 2019, Wang et al., 2019c). These experts have indicated a need to measure green and blue space not only with remote-sensed data, but also with street-level views that can capture individuals' visual experience of green space and blue space. Only with such a perspective is it possible to accurately assess the effects of neighbourhood natural outdoor environments on physical and mental health (Lu, 2018, Ye et al., 2018, Lu et al., 2019). Furthermore, the recent established life-course framework (Pearce et al., 2018, Helbich, 2018, Nieuwenhuijsen, 2016) is essential to understand the relationship between natural outdoor environments and individual's mental health. It underlines the accumulation effect of natural outdoor environment over an individual's life and reveals significant periods with stronger exposure effects.

Our findings confirmed our Hypothesis 1 and Hypothesis 2. They supported previous research showing that both neighbourhood green space and blue space can reduce the risk of mental illness, and that both kinds of space exert a beneficial influence on mental health (Laumann et al., 2003, Pretty et al., 2005, Nielsen and Hansen, 2007, Karmanov and Hamel, 2008, de Vries et al., 2013, Hartig et al., 2014, Markevych et al., 2017). Our findings also suggested that the failure of previous 
studies to confirm an association between neighbourhood natural outdoor environments and mental health may have resulted from using inappropriate measures. For instance, Nielsen and Hansen (2007) and Mitchell (2013) found that regular visits to neighbourhood natural outdoor environments were not associated with greater mental health. In those studies, however, the measures used were incapable either of capturing the characteristics of the natural outdoor environment or of assessing the outcomes of exposure to those environments. Therefore, our study has highlighted the need to analyse the relationship between neighbourhood natural outdoor environment and individuals' mental health in a way that focuses on the 'human scale' (i.e., a scale related to the human body) and captures the visible and touchable features of the surrounding neighbourhood natural outdoor environment as they are experienced in an individual's daily life (Ye et al., 2018, Lu, 2018).

\subsection{The mediating effects from different dimensions of neighbourhood social cohesion}

The existing research has proposed that neighbourhood social cohesion exerts a mediating effect through which the neighbourhood natural outdoor environment influences individuals' mental health (Sugiyama et al., 2008, Maas et al. 2009, de Vries et al., 2013, Nutsford et al., 2015). In our study, we went one step further by observing the mediation impacts from the three dimensions of neighbourhood social cohesion (i.e. neighbourhood attachment, neighbourly interaction, and community participation) on the association between neighbourhood outdoor environment and mental health. Our findings revealed an indirect impact of neighbourhood street view greenness on mental health, via facilitating neighbourhood attachment and community participation.

We initially assumed that neighbourhood blue space also had an indirect influence on mental health, through facilitating social cohesion, as suggested by previous studies (Maas et al., 2009, Peters et al., 2010, de Bell et al., 2017). Unexpectedly, we found no evidence to support this notion. Our findings suggest that neighbourhood blue space is positively associated with mental health, but not with social cohesion in Guangzhou. Residents in Guangzhou are less likely to use riversides or lakes for social interactions. Also, the sampled neighbourhoods of Guangzhou had relatively little blue 
space (the neighbourhood street view blueness index was 0.004 and the GlobeLand 30 blueness index was 0.058). The lack of large blue space may lead to inconsistent findings compared with previous studies.

\subsection{Strengths and limitations}

This study is one of the first to examine the relationship between neighbourhood natural outdoor environment and individuals' mental health in Chinese cities. It has three major strengths. First, we measured natural environment exposure from both street view images, and remote-sensing data. Second, we explored how three dimensions of neighbourhood social cohesion mediate the association between natural environment and mental health. Third, this research provided insights for policymakers and urban planners on creating healthy urban environment in Guangzhou and other densely developed cities in developing countries, which often featuring rapid urbanisation and large migrant populations.

Three limitations of this research should be mentioned. First, the effects of neighbourhood natural environment on mental health might have been overestimated, due to the cross-sectional research design. Individuals favouring natural environment may choose to live in neighbourhoods featuring abundant natural environment, and hence the observed associations between green and blue spaces and mental health might be spurious. Second, our results may be biased because we did not collect data on certain relevant individual variables, i.e., personalities and preferences for green/blue spaces, which may also be associated with individuals' mental health. Third, our research focuses on the mediation pathways of different dimensions of neighbourhood social cohesion; however, there are other important pathways for which remote-sensing metrics may be more relevant to, such as mitigation of air pollution (Markevych et al. 2017).

\section{Declaration of Competing Interest}

The authors declare that the research was conducted in the absence of any commercial or financial relationships that could be construed as a potential conflict of interest. 


\section{Acknowledgement:}

This work was supported by the National Natural Science Foundation of China [41871140, 41871161,51578474,41771167]. 


\section{References}

AlCOCK, I., White, M. P., LOVELl, R., HIGGINS, S. L., OSBORNE, N. J., HUSK, K. \& WHEELER, B. W. 2015. What accounts for 'England's green and pleasant land'? A panel data analysis of mental health and land cover types in rural England. Landscape and Urban Planning, $142,38-46$.

ARSANJANI, J. J., ZIPF, A., MOONEY, P. \& HELBICH, M. 2015. An introduction to OpenStreetMap in Geographic Information Science: Experiences, research, and applications. OpenStreetMap in GIScience. Springer.

ASTELL-BURT, T., MITCHELL, R. \& HARTIG, T. 2014. The association between green space and mental health varies across the lifecourse. A longitudinal study. J Epidemiol Community Health, $68,578-583$.

BARTON, H., THOMPSON, S., BURGESS, S. \& GRANT, M. 2015. The Routledge handbook of planning for health and well-being: Shaping a sustainable and healthy future, Routledge.

BAUMAN, A. E., REIS, R. S., SALLIS, J. F., WELLS, J. C., LOOS, R. J. F. \& MARTIN, B. W. 2012. Correlates of physical activity: why are some people physically active and others not? The Lancet, 380, 258-271.

BERKMAN, L. F., GLASS, T., BRISSETTE, I. \& SEEMAN, T. E. 2000. From social integration to health: Durkheim in the new millennium. Social Science \& Medicine, 51, 843-857.

BERRY, H. L., RODGERS, B. \& DEAR, K. B. G. 2007. Preliminary development and validation of an Australian community participation questionnaire: Types of participation and associations with distress in a coastal community. Social Science \& Medicine, 64, 1719-1737.

BEYER, K. M., KALTENBACH, A., SZABO, A., BOGAR, S., NIETO, F. J. \& MALECKI, K. M. 2014. Exposure to neighborhood green space and mental health: evidence from the survey of the health of Wisconsin. International journal of environmental research and public health, 11, $3453-3472$

BOERS, S., HAGOORT, K., SCHEEPERS, F. \& HELBICH, M. 2018. Does residential green and blue space promote recovery in psychotic disorders? A cross-sectional study in the province of Utrecht, the Netherlands. International journal of environmental research and public health, 15, 2195.

CHAN, D. W. 1985. The Chinese version of the General Health Questionnaire: does language make a difference?. Psychological medicine, 15, 147-155.

CHEN, J., CHEN, J., LIAO, A., CAO, X., CHEN, L., CHEN, X., He, C., HAN, G., PENG, S., LU, M., ZHANG, W., TONG, X. \& MILLS, J. 2015.Global land cover mapping at $30 \mathrm{~m}$ resolution: A POK-based operational approach. ISPRS Journal of Photogrammetry and Remote Sensing, 103, 7-27. 
DE BELL, S., GRAHAM, H., JARVIS, S. \& WHITE, P. 2017. The importance of nature in mediating social and psychological benefits associated with visits to freshwater blue space. Landscape and Urban Planning, 167, 118-127.

DE KEIJZER, C., TONNE, C., SABIA, S., BASAGAÑA, X., VALENTÍN, A., SINGH-MANOUX, A., ANTÓ, J. M., ALONSO, J., NIEUWENHUIJSEN, M. J., SUNYER, J. \& DADVAND, P. 2019. Green and blue spaces and physical functioning in older adults: Longitudinal analyses of the Whitehall II study. Environment international, 122, 346-356.

DE VRIES, S., VAN DILlEN, S. M., GROENEWEGEN, P. P. \& SPREEUWENBERG, P. 2013. Streetscape greenery and health: stress, social cohesion and physical activity as mediators. Social Science \& Medicine, 94, 26-33.

DEMPSEY, S., DEVINE, M. T., GILLESPIE, T., LYONS, S. \& NOLAN, A. 2018. Coastal blue space and depression in older adults. Health \& Place, 54, 110-117.

DING, N., BERRY, H. L. \& O'BRIEN, L. V. 2015. One-year reciprocal relationship between community participation and mental wellbeing in Australia: A panel analysis. Social Science \& Medicine, $128,246-254$.

DZHAMBOV, A. M., MARKEVYCH, I., TILOV, B. G. \& DIMITROVA, D. D. 2018. Residential greenspace might modify the effect of road traffic noise exposure on general mental health in students. Urban forestry \& urban greening, 34, 233-239.

DZHAMBOV, A., HARTIG, T., MARKEVYCH, I., TILOV, B., \& DIMITROVA, D. (2018). Urban residential greenspace and mental health in youth: different approaches to testing multiple pathways yield different conclusions. Environmental research, 160, 47-59.

ENDERS, C. K. \& TOFIGHI, D. 2007. Centering predictor variables in cross-sectional multilevel models: a new look at an old issue. Psychological methods, 12, 121-138.

FOLEY, R. \& KISTEMANN, T. 2015. Blue space geographies: Enabling health in place. Health \& Place, $35,157-165$.

FORREST, R. \& KEARNS, A. 2001. Social Cohesion, Social Capital and the Neighbourhood. Urban Studies, 38, 2125-2143.

FRANCIS, J., WOOD, L. J., KNUIMAN, M. \& GILES-CORTI, B. 2012. Quality or quantity? Exploring the relationship between Public Open Space attributes and mental health in Perth, Western Australia. Social Science \& Medicine, 74, 1570-1577.

FRIEDKIN, N. E. 2004. Social Cohesion. Annual Review of Sociology, 30, 409-425.

GALE, C. R., DENNISON, E. M., COOPER, C. \& SAYER, A. A. 2011. Neighbourhood environment and positive mental health in older people: The Hertfordshire Cohort Study. Health \& Place, 17, 867-874. 
GASCON, M., ZIJLEMA, W., VERT, C., WHITE, M. P. \& NIEUWENHUIJSEN, M. J. 2017. Outdoor blue spaces, human health and well-being: A systematic review of quantitative studies. International Journal of Hygiene and Environmental Health, 220, 1207-1221.

GELMAN, A. \& HILL, J. 2006. Data Analysis Using Regression and Multilevel/Hierarchical Models, New York, Cambridge University Press.

GOLDBERG, D. P. \& HILLIER, V. F. 1979. A scaled version of the General Health Questionnaire. Psychological Medicine, 9, 139-145.

GROUP, T. E. 1990. EuroQol-a new facility for the measurement of health-related quality of life. Health policy, 16, 199-208.

GREINER, K. A., LI, C., KAWACHI, I., HUNT, D. C. \& AHLUWALIA, J. S. 2004. The relationships of social participation and community ratings to health and health behaviors in areas with high and low population density. Social Science \& Medicine, 59, 2303-2312.

HAEFFNER, M., JACKSON-SMITH, D., BUCHERT, M. \& RISLEY, J. 2017. Accessing blue spaces: Social and geographic factors structuring familiarity with, use of, and appreciation of urban waterways. Landscape and Urban Planning, 167, 136-146.

HARTIG, T., MANG, M. \& EVANS, G. W. 1991. Restorative Effects of Natural Environment Experiences. Environment and Behavior, 23, 3-26.

HARTIG, T., MITCHELL, R., VRIES, S. D. \& FRUMKIN, H. 2014. Nature and Health. Annual Review of Public Health, 35, 207-228.

HAUCK, K., \& RICE, N. (2004). A longitudinal analysis of mental health mobility in Britain. Health economics, 13(10), 981-1001.

HELBICH, M., KLEIN, N., ROBERTS, H., HAGEDOORN, P. \& GROENEWEGEN, P. P. 2018. More green space is related to less antidepressant prescription rates in the Netherlands: A Bayesian geoadditive quantile regression approach. Environmental research, 166, 290-297.

HELBICH, M. 2018. Toward dynamic urban environmental exposure assessments in mental health research. Environmental research, 161, 129-135.

HELBICH, M., YAO, Y., LIU, Y., ZHANG, J., LIU, P. \& WANG, R. 2019. Using deep learning to examine street view green and blue spaces and their associations with geriatric depression in Beijing, China. Environment international, 126, 107-117.

JIA, X., YU, Y., XIA, W., MASRI, S., SAMI, M., HU, Z., YU, Z. \& WU, J. 2018. Cardiovascular diseases in middle aged and older adults in China: the joint effects and mediation of different types of physical exercise and neighborhood greenness and walkability. Environmental research, $167,175-183$.

JUN, C., BAN, Y. \& LI, S. 2014. Open access to Earth land-cover map. Nature, 514, 434 
doi: $10.1038 / 514434 c$.

KARMANOV, D. \& HAMEL, R. 2008. Assessing the restorative potential of contemporary urban environment(s): Beyond the nature versus urban dichotomy. Landscape and Urban Planning, $86,115-125$.

KAWACHI, I. \& BERKMAN, L. F. 2001. Social ties and mental health. Journal of Urban health, 78, 458-467.

KAWACHI, I., KENNEDY, B. P. \& GLASS, R. 1999. Social capital and self-rated health: a contextual analysis. American Journal of Public Health, 89, 1187-1193.

KEARNS, A. \& FORREST, R. 2000. Social Cohesion and Multilevel Urban Governance. Urban Studies, 37, 995-1017.

LAUMANN, K., GÄRLING, T. \& STORMARK, K. M. 2003. Selective attention and heart rate responses to natural and urban environments. Journal of Environmental Psychology, 23, 125134.

LECUN, Y., BENGIO, Y. \& HINTON, G. 2015. Deep learning. Nature, 521, 436.

LEWICKA, M. 2011. Place attachment: How far have we come in the last 40 years? Journal of Environmental Psychology, 31, 207-230.

LIU, H., LI, F., LI, J. \& ZHANG, Y. 2017a. The relationships between urban parks, residents' physical activity, and mental health benefits: A case study from Beijing, China. Journal of environmental management, 190, 223-230.

LIU, Y., ZHANG, F., WU, F., LIU, Y., \& LI, Z. 2017b. The subjective wellbeing of migrants in Guangzhou, China: the impacts of the social and physical environment. Cities, 60, 333-342.

LIU, Y., WANG, R., GREKOUSIS, G., LIU, Y., YUAN, Y. \& LI, Z. 2019a. Neighbourhood greenness a nd mental wellbeing in Guangzhou, China: What are the pathways? Landscape and Urban Pla nning, 190, 103602

LIU, Y., WANG, R., XIAO, Y., HUANG, B., CHEN, H., \& LI, Z. 2019b. Exploring the linkage between greenness exposure and depression among Chinese people: Mediating roles of physical activity, stress and social cohesion and moderating role of urbanicity. Health \& place, 58, 102168.

LIU, Y., ZHANG, F., LIU, Y., LI, Z., \& WU, F. 2019c. Economic disadvantages and migrants' subjective well - being in China: The mediating effects of relative deprivation and neighbourhood deprivation. Population, Space and Place, 25(2), e2173.

LI, W. H., CHUNG, J. O., CHUI, M. M., \& CHAN, P. S. 2009. Factorial structure of the Chinese version of the 12 - item General Health Questionnaire in adolescents. Journal of Clinical Nursing, 18, 3253-3261. 
LONG, J., SHELHAMER, E. \& DARRELL, T. Fully convolutional networks for semantic segmentation. Proceedings of the IEEE conference on computer vision and pattern recognition, 2015. 34313440.

LONG, Y. \& LIU, L. 2017. How green are the streets? An analysis for central areas of Chinese cities using Tencent Street View. Plos One, 12, e0171110.

LU, Y. 2018. Using Google Street View to investigate the association between street greenery and physical activity. Landscape and Urban Planning.

LU, Y., YANG, Y., SUN, G., \& GOU, Z. 2019. Associations between overhead-view and eye-level urban greenness and cycling behaviors. Cities, 88, 10-18.

MA, J., MITCHELL, G., DONG, G. \& ZHANG, W. 2017. Inequality in Beijing: A spatial multilevel analysis of perceived environmental hazard and self-rated health. Annals of the American Association of Geographers, 107, 109-129.

MAAS, J., VAN DILLEN, S. M., VERHEIJ, R. A. \& GROENEWEGEN, P. P. 2009. Social contacts as a possible mechanism behind the relation between green space and health. Health \& Place, 15, 586-595.

MARKEVYCH, I., SCHOIERER, J., HARTIG, T., CHUDNOVSKY, A., HYSTAD, P., DZHAMBOV, A. M., DE VRIES, S., TRIGUERO-MAS, M., BRAUER, M. \& NIEUWENHUIJSEN, M. J. 2017. Exploring pathways linking greenspace to health: theoretical and methodological guidance. Environmental research, 158, 301-317.

MCFEETERS, S. K. 1996. The use of the Normalized Difference Water Index (NDWI) in the delineation of open water features. International Journal of Remote Sensing, 17, 1425-1432.

MCMILLAN, D.W. \& CHAVIS, D.M. 1986. Sense of community: A definition and theory. Journal of Community Psychology,14,6-23.

MITCHELL, R. 2013. Is physical activity in natural environments better for mental health than physical activity in other environments?. Social Science \& Medicine, 91, 130-134.

NETUVELI, G., WIGGINS, R. D., MONTGOMER, S. M., HILDON, Z., \& BLANE, D. (2008). Mental health and resilience at older ages: Bouncing back after adversity in the British Household Panel Survey. Journal of Epidemiology \& Community Health, 62(11), 987-991.

NIELSEN, T. S. \& HANSEN, K. B. 2007. Do green areas affect health? Results from a Danish survey on the use of green areas and health indicators. Health \& Place, 13, 839-850.

NIEUWENHUIJSEN, M. J. 2016. Urban and transport planning, environmental exposures and healthnew concepts, methods and tools to improve health in cities. Environmental health, 15(1), S38.

NOWAK, D. J., HIRABAYASHI, S., BODINE, A. \& GREENFIELD, E. 2014. Tree and forest effects on air quality and human health in the United States. Environmental Pollution, 193, 119-129. 
NUTSFORD, D., PEARSON, A. L. \& KINGHAM, S. 2013. An ecological study investigating the association between access to urban green space and mental health. Public Health, 127, 10051011.

NUTSFORD, D., REITSMA, F., PEARSON, A. L. \& KINGHAM, S. 2015. Personalising the viewshed: Visibility analysis from the human perspective. Applied Geography, 62, 1-7.

NUTSFORD, D., PEARSON, A. L., KINGHAM, S. \& REITSMA, F. 2016. Residential exposure to visible blue space (but not green space) associated with lower psychological distress in a capital city. Health \& Place, 39, 70-78.

PATEL, V., FLISHER, A. J., HETRICK, S. \& MCGORRY, P. 2007. Mental health of young people: a global public-health challenge. The Lancet, 369, 1302-1313.

PETERS, K., ELANDS, B. \& BUIJS, A. 2010. Social interactions in urban parks: stimulating social cohesion? Urban forestry \& urban greening, 9, 93-100.

PRETTY, J., PEACOCK, J., SELLENS, M. \& GRIFFIN, M. 2005. The mental and physical health outcomes of green exercise. International Journal of Environmental Health Research, 15, 319337.

RAUDENBUSH, S. W. \& BRYK., A. S. 2002. Hierarchical Linear Models: Applications and Data Analysis Methods, Thousand Oaks, US, Sage Publications.

RYU, E., \& WEST, S. G. 2009. Level-specific evaluation of model fit in multilevel structural equation modeling. Structural Equation Modeling, 16, 583-601.

SAMPSON, R.J., RAUDENBUSH, S.W. and EARLS, F., 1997. Neighborhoods and violent crime: A multilevel study of collective efficacy. Science, 277, 918-924.

SCANNELL, L. \& GIFFORD, R. 2010. Defining place attachment: A tripartite organizing framework. Journal of Environmental Psychology, 30, 1-10.

SCANNELL, L. \& GIFFORD, R. 2017. The experienced psychological benefits of place attachment. Journal of Environmental Psychology, 51, 256-269.

SU, S., ZHANG, Q., PI, J., WAN, C. \& WENG, M. 2016. Public health in linkage to land use: Theoretical framework, empirical evidence, and critical implications for reconnecting health promotion to land use policy. Land Use Policy, 57, 605-618.

SUGIYAMA, T., LESLIE, E., GILES-CORTI, B. \& OWEN, N. 2008. Associations of neighbourhood greenness with physical and mental health: do walking, social coherence and local social interaction explain the relationships? Journal of Epidemiology \& Community Health, 62, e9-e9.

TENNANT, R., HILLER, L., FISHWICK, R., PLATT, S., JOSEPH, S., WEICH, S., PARKINSON, J., SECKER, J. \& STEWART-BROWN, S. 2007. The Warwick-Edinburgh mental well-being scale (WEMWBS): development and UK validation. Health and Quality of life Outcomes, 5, 63. 
TENCENT MAP. 2015. Accessed September 30"th 2015 , < https://map.qq.com >.

TRIGUERO-MAS, M., DADVAND, P., CIRACH, M., MARTÍNEZ, D., MEDINA, A., MOMPART, A., BASAGAÑA, X., GRAŽULEVIČIENĖ, R. \& NIEUWENHUIJSEN, M. J. 2015. Natural outdoor environments and mental and physical health: relationships and mechanisms. Environment international, 77, 35-41.

ULRICH, R. S., SIMONS, R. F., LOSITO, B. D., FIORITO, E., MILES, M. A. \& ZELSON, M. 1991. Stress recovery during exposure to natural and urban environments. Journal of Environmental Psychology, 11, 201-230.

VAN DEN BERG, A. E., MAAS, J., VERHEIJ, R. A. \& GROENEWEGEN, P. P. 2010. Green space as a buffer between stressful life events and health. Social Science \& Medicine, 70, 1203-1210.

VAN DEN BERG, M., VAN POPPEL, M., SMITH, G., TRIGUERO-MAS, M., ANDRUSAITYTE, S., VAN KAMP, I., VAN MECHELEN, W., GIDLOW, C., GRAŽULEVIČIENE, R., NIEUWENHUIJSEN, M. J., KRUIZE, H. \& MAAS, J. 2017. Does time spent on visits to green space mediate the associations between the level of residential greenness and mental health? Urban forestry \& urban greening, 25, 94-102.

VÖLKER, B., FLAP, H., \& LINDENBERG, S. (2006). When are neighbourhoods communities? Community in Dutch neighbourhoods. European Sociological Review, 23, 99-114.

WANG, R., LU, Y., ZHANG, J., LIU, P., YAO, Y. \& LIU, Y. 2019a. The relationship between visual enclosure for neighbourhood street walkability and elders' mental health in China: Using street view images. Journal of Transport \& Health, 13, 90-102.

WANG, R., YANG, B., YAO, Y., BLOOM, M. S., FENG, Z., YUAN, Y., ZHANG, J., LIU, P., WU, W., LU, Y., BARANYI, G., WU, R., LIU, Y. \& DONG, G. 2019b. Residential greenness, air pollu tion and psychological wellbeing among urban residents in Guangzhou, China. Science of The Total Environment, 134843.

WANG, R., HELBICH, M., YAO, Y., ZHANG, J., LIU, P., YUAN, Y. \& LIU, Y. 2019c. Urban greener $\mathrm{y}$ and mental wellbeing in adults: Crosssectional mediation analyses on multiple pathways acr oss different greenery measures. Environmental Research, 176, 108535.

THOMPSON, C. W., ROE, J., ASPINALL, P., MITCHELL, R., CLOW, A. \& MILLER, D. 2012. More green space is linked to less stress in deprived communities: Evidence from salivary cortisol patterns. Landscape and Urban Planning, 105, 221-229.

WHO.2010. Global recommendations on physical activity for health. World Health Organization, Geneva.

WHO.2016. Urban Green Spaces and Health. A Review of Evidence. WHO Regional Office for Europe, Copenhagen. 
WHO. 2017. Urban Green Spaces: A Brief for Action. WHO Regional Office for Europe, Copenhagen.

WU, W. \& DONG, G. 2013. Valuing the "green" amenities in a spatial context. Journal of Regional Science, n/a-n/a.

XIAO, Y., LU, Y., GUO, Y., \& YUAN, Y. 2017. Estimating the willingness to pay for green space services in Shanghai: Implications for social equity in urban China. Urban Forestry \& Urban Greening, 26, 95-103.

YANG, L., XIAN, G., KLAVER, J. M. \& DEAL, B. 2003. Urban land-cover change detection through sub-pixel imperviousness mapping using remotely sensed data. Photogrammetric Engineering \& Remote Sensing, 69, 1003-1010.

YE, Y., RICHARDS, D., LU, Y., SONG, X., ZHUANG, Y., ZENG, W. \& ZHONG, T. 2018. Measuring daily accessed street greenery: A human-scale approach for informing better urban planning practices. Landscape and Urban Planning.

ZHOU, B., ZHAO, H., PUIG, X., FIDLER, S., BARRIUSO, A. \& TORRALBA, A. 2017. Scene parsing through ade20k dataset. Proceedings of the IEEE Conference on Computer Vision and Pattern Recognition, 633-641.

ZHOU, B., ZHAO, H., PUIG, X., XIAO, T., FIDLER, S., BARRIUSO, A. \& TORRALBA, A. 2019. Semantic understanding of scenes through the ade20k dataset. International Journal of Computer Vision, 127, 302-321.

ZHU, Y. \& FU, Q. 2017. Deciphering the civic virtue of communal space: Neighborhood attachment, social capital, and neighborhood participation in urban China. Environment and Behavior, 49, 161-191. 


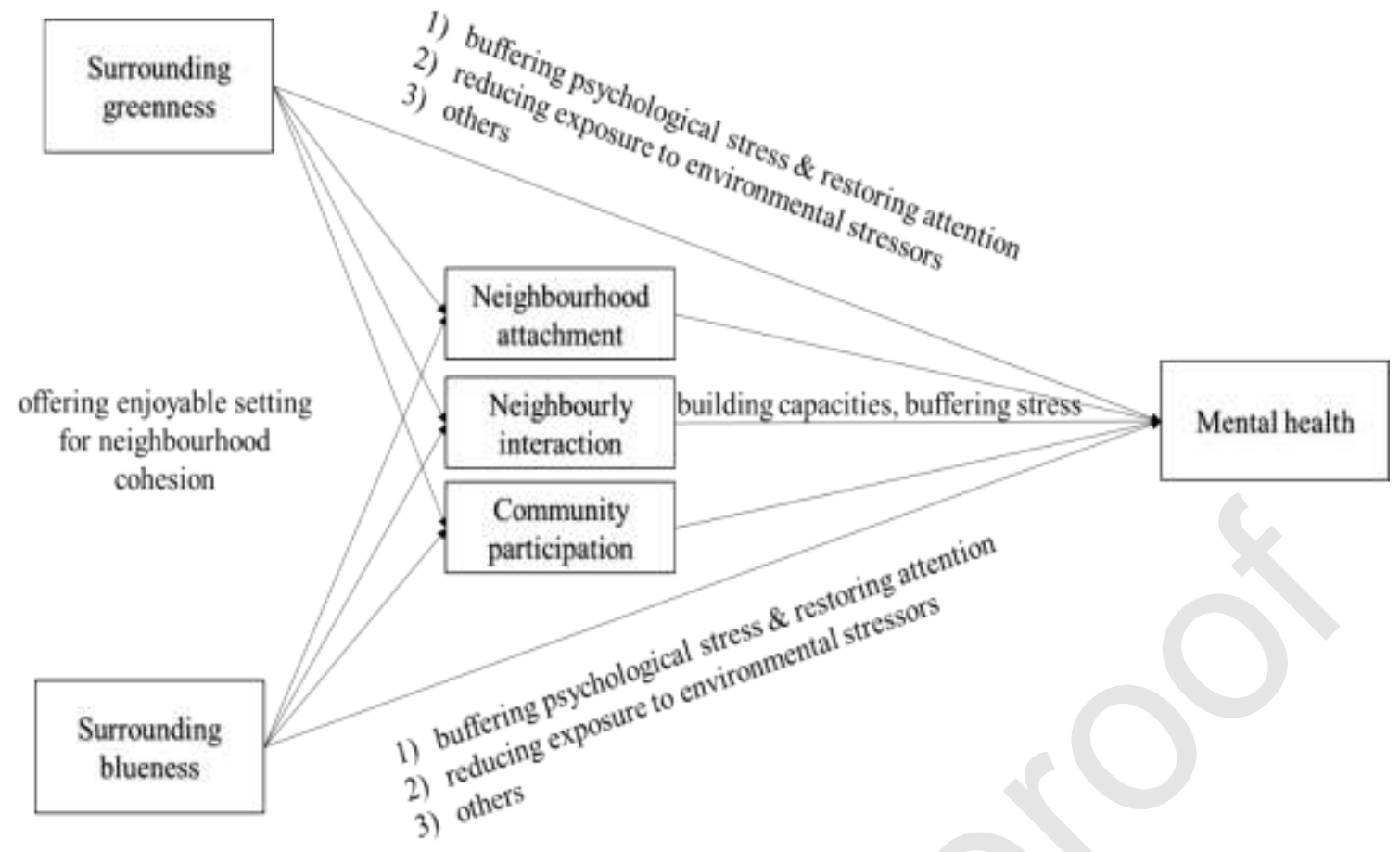

Figure 1. Conceptual framework of the relationship between surrounding natural outdoor environment, neighbourhood social cohesion, and mental health

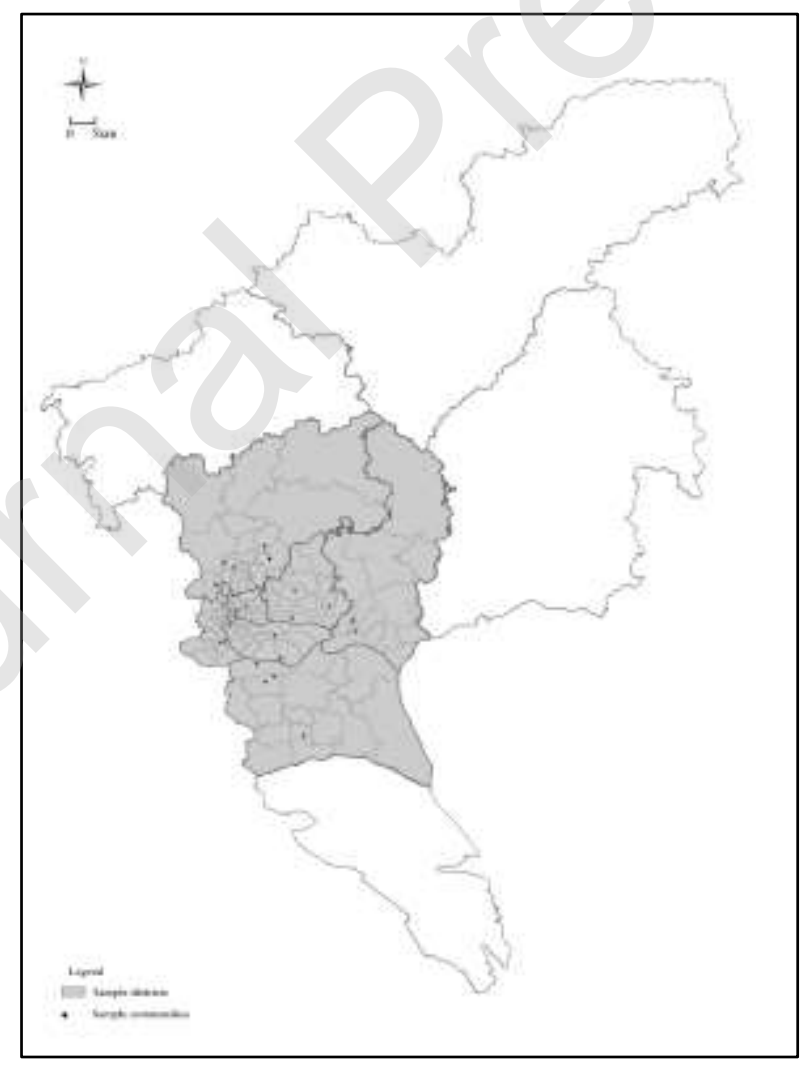

Figure 2. The spatial location of 23 sampled residential neighbourhoods in Guangzhou, China 


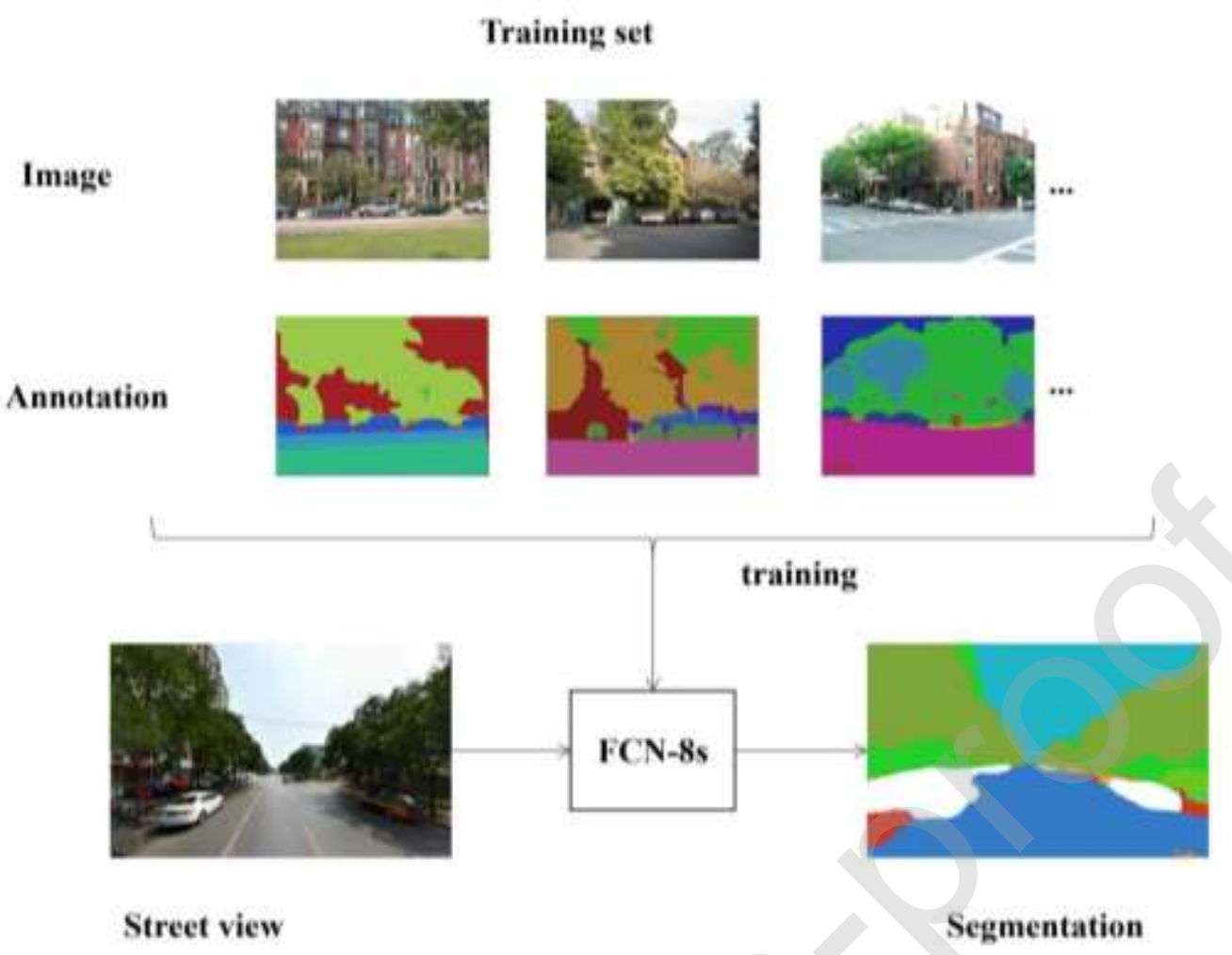

Figure 3. Street view image segmentation through a fully convolutional network (FCN-8s). 
Table 1. Summary characteristics of three dimensions of neighbourhood social cohesion.

Dimension

Description

Proportion/Me

an (SD)

\section{Neighbourhood attachment}

Indicator 1

Indicator 2

Indicator 3

To what extent do you agree with the following statements about the attachment to your neighbourhood? (1-5 Likert scale, $1=$ strongly disagree, $5=$ totally agree)

I belong to this neighbourhood.

$3.637(0.818)$

I am attached to this neighbourhood.

$3.752(0.722)$

I like the living environments of this neighbourhood.

$3.548(0.875)$

Indicator 4

I am concerned with the reports of my neighbourhood in the newspapers and television channels.

Indicator 5

It is very important to me to be a member of the neighbourhood.

Indicator 6

I am willing to reside in this neighbourhood for the long term.

Developing connections with other members of the neighbourhood is

Indicator 7 important to me.

\section{Neighbourly interaction}

Indicator 8

How often do you greet your neighbours? (1-5 Likert scale, $1=$ never, $5=$ =always)

How often do you visit and chat with your neighbours? (1-5 Likert scale, $1=$ never, 5 = always)

Indicator 9

\section{Community participation}

Indicator 10

Indicator 11

Participate in activities organized by community grassroots organizations.

Vote in the elections of community organizations such as neighborhood committees and village committees.

Indicator 12

Participate in volunteer organizations. 
Table 2. Summary statistics of the variables

\section{Dependent variables}

GHQ Score (12-48)

\section{Independent variables}

Street view greenness $(0-1)$ median (IQR)

$0.235(0.081)$

Street view blueness $(0-1)$ median (IQR)

$0.004(0.003)$

Surrounding green space: GlobeLand30 greenness (0-1)

$0.191(0.243)$

Surrounding blue space: GlobeLand30 blueness (0-1)

$0.058(0.081)$

Neighbourhood attachment (7-35)

$26.205(3.922)$

Neighbourly interaction (2-10)

$6.113(1.649)$

Neighbourhood participation (6-30)

$12.166(4.041)$ 


\section{Controlled variables}

Gender (\%)

Male 52.261

Female

47.739

Age

$39.553(11.065)$

Education (\%)

Primary school or below

High school

60.174

College and above

34.696

Marital status (\%)

Single, divorced or widowed

20.000

Married

80.000

Hukou status (\%)

Local hukou

59.391

Non-local hukou

40.609

Employment status

Employed

83.913

Unemployed

16.087

Medical insurance

Yes

No

13.478

Annual household income per household member (CNY)

46,251.866 (200,111.785) 
Table 3. Multilevel SEMs: The association between street view greenness (blueness) exposure and mental health.

Variable

Model 1

\begin{tabular}{|c|c|c|c|}
\hline \multirow[t]{2}{*}{ GHQ } & Neighbourhood & Neighbourly & Community \\
\hline & attachment & interaction & participation \\
\hline
\end{tabular}

Independent variables

Street view greenness

Street view blueness

Neighbourhood attachment

Neighbourly interaction

Community participation

Controlled variables

Male (ref: female)

Age

Education (ref: primary school or less)

High school

College or more

Married (ref. $=$ single, divorced or widowed $)$

Local hukou (ref: non-local hukou)

Employed (ref: unemployed)

With medical insurance (ref: without medical insurance)

Logarithm of annual household income per household member
Estimate (S.E.) Estimate (S.E.) Estimate (S.E.) Estimate (S.E.)

$$
\begin{aligned}
& -0.900 * *(0.419) \\
& -0.406 * *(0.193) \\
& -0.214 * * *(0.044) \\
& -0.119(0.103) \\
& -0.165 * * *(0.043)
\end{aligned}
$$$$
0.741 * * *(0.187)
$$$$
0.046(0.080)
$$$$
-0.122(0.086)
$$$$
0.413(0.306)
$$$$
-0.406 * *(0.193) \quad 0.113(0.202)
$$

Estimate (S.E.)

$0.185 * *(0.081)$

$0.413(0.306)$

)


RMSEA for multilevel (single-level) SEMs

CFI for multilevel (single-level) SEMs
$0.039(0.036)$

$0.909(0.935)$

Notes: 1$) * p<0.1, * * p<0.05, * * * p<0.01$

2) A higher total score of GHQ suggests a worse mental health status

Table 4. Multilevel SEMs: The association between GlobeLand30 greenness (blueness) exposure and mental health.

Variable

Model 2

\begin{tabular}{llll}
\hline GHQ & Neighbourhood & Neighbourly & Community \\
& attachment & interaction & participation \\
Estimate (S.E.) & Estimate (S.E.) & Estimate (S.E.) & Estimate (S.E.)
\end{tabular}

Independent variables

GlobeLand30 greenness

GlobeLand30 blueness
$-2.369 * *(1.029) \quad 1.538(1.453)$

$-5.348 *(3.085)$

$1.686(1.348)$ 
Neighbourhood attachment

Neighbourly interaction

Community participation

Controlled variables

Male (ref: female)

Age

Education (ref: primary school or less)

High school

College or more

Married (ref. $=$ single, divorced or widowed)

Local hukou (ref: non-local hukou)

Employed (ref: unemployed)

With medical insurance (ref: without medical insurance) household member $-0.034(0.188)$

$-0.138(0.103)$
Logarithm of annual household income per

$-0.229 * * *(0.044)$

$-0.166 * * *(0.043)$

$\begin{array}{llll}-0.222(0.300) & -0.337(0.222) & -0.210 * *(0.093) & -0.261(0.223) \\ 0.022(0.018) & 0.031 * *(0.013) & 0.022 * * *(0.005) & 0.047 * * *(0.013)\end{array}$

$-0.834(0.694) \quad-0.333(0.512) \quad-0.208(0.215)$

$-0.056(0.515)$

$-1.730 * *(0.786) \quad 0.780(0.572) \quad 0.011(0.240)$

$1.154 * *(0.575)$

$$
\begin{array}{llll}
-0.467(0.418) & 0.170(0.305) & 0.338 * * *(0.128) & -0.131(0.307) \\
-0.202(0.379) & 1.312 * * *(0.267) & 0.180(0.112) & 1.270 * * *(0.269) \\
-0.704(0.446) & -0.290(0.326) & -0.060(0.136) & -0.469(0.327)
\end{array}
$$

$-0.570(0.495)$

$0.957 * * *(0.346)$

$0.308 * *(0.145)$

$1.667 * * *(0.348)$

RMSEA for multilevel (single-level) SEMs

CFI for multilevel (single-level) SEMs
$0.182(0.129) \quad-0.284 * * *(0.054) \quad-0.426 * * *(0.13)$

$0.037(0.035)$

$0.907(0.921)$

Notes: 1$)^{*} p<0.1, * * p<0.05, * * * p<0.01$

2) A higher total score of GHQ suggests a worse mental health status 
Table 5. Multilevel SEMs: The direct and indirect effects of neighbourhood street-level greenness (blueness) and surrounding amount of green space (blue space) on mental health

\begin{tabular}{|c|c|c|c|c|}
\hline & \multicolumn{4}{|c|}{ Model 1} \\
\hline & & Indirect effect & & Direct effect \\
\hline & $\begin{array}{l}\text { Neighbourhood } \\
\text { attachment }\end{array}$ & $\begin{array}{l}\text { Neighbourly } \\
\text { interaction }\end{array}$ & $\begin{array}{l}\text { Community } \\
\text { participation }\end{array}$ & \\
\hline Mediator & Estimate (S.E.) & Estimate (S.E.) & Estimate (S.E.) & Estimate (S.E.) \\
\hline Street view greenness & $-0.153 * * *(0.051)$ & $-0.005(0.010)$ & $-0.031 * *(0.015)$ & $-0.900 * *(0.419)$ \\
\hline \multirow[t]{6}{*}{ Street view blueness } & $-0.024(0.043)$ & $0.015(0.016)$ & $-0.068(0.053)$ & $-0.406 * *(0.193)$ \\
\hline & \multicolumn{4}{|c|}{ Model 2} \\
\hline & \multicolumn{3}{|c|}{ Indirect effect } & Direct effect \\
\hline & Neighbourhood & Neighbourly & Community & \\
\hline & attachment & interaction & participation & \\
\hline & Estimate (S.E.) & Estimate (S.E.) & Estimate (S.E.) & Estimate (S.E.) \\
\hline GlobeLand30 greenness & $-0.352(0.339)$ & $-0.125(0.096)$ & $-0.292(0.253)$ & $-2.369 * *(1.029)$ \\
\hline GlobeLand30 blueness & $-0.386(0.317)$ & $-0.198(0.167)$ & $-0.158(0.228)$ & $-5.348 *(3.085)$ \\
\hline
\end{tabular}

Notes: 1$) * p<0.1, * * p<0.05, * * * p<0.01$

2) A higher total score of GHQ suggests a worse mental health status

Table 6. Sensitivity check: The association between street view greenness (blueness) exposure and mental health. 


\begin{tabular}{llll}
\hline & $\begin{array}{l}\text { Neighbourhood } \\
\text { attachment }\end{array}$ & Neighbourly & Community \\
interaction & participation
\end{tabular}

Estimate (S.E.) $\quad$ Estimate (S.E.) $\quad$ Estimate (S.E.) $\quad$ Estimate (S.E.)

\begin{tabular}{|c|c|c|c|c|}
\hline \multicolumn{5}{|l|}{ Independent variables } \\
\hline Street view greenness & $-0.696^{* *}(0.341)$ & $0.806^{* * * *}(0.200)$ & $0.056(0.086)$ & $0.088 * *(0.042)$ \\
\hline Street view blueness & $-0.379 * *(0.174)$ & $0.162(0.322)$ & $-0.182(0.138)$ & $0.256(0.329)$ \\
\hline Neighbourhood attachment & $-0.213 * * *(0.044)$ & & & \\
\hline Neighbourly interaction & $-0.123(0.103)$ & & & \\
\hline Community participation & $-0.166 * * *(0.043)$ & & & \\
\hline \multicolumn{5}{|l|}{ Controlled variables } \\
\hline Male (ref: female) & $-0.229(0.300)$ & $-0.260(0.220)$ & $-0.205 * *(0.094)$ & $-0.257(0.225)$ \\
\hline Age & $0.023(0.018)$ & $0.025 * *(0.013)$ & $0.022 * * *(0.005)$ & $0.047 * * *(0.013)$ \\
\hline \multicolumn{5}{|l|}{ Education (ref: primary school or less) } \\
\hline High school & $-0.814(0.694)$ & $-0.519(0.507)$ & $-0.236(0.217)$ & $-0.090(0.519)$ \\
\hline College or more & $-1.603 * *(0.786)$ & $0.432(0.568)$ & $0.015(0.243)$ & $1.141 * *(0.581)$ \\
\hline $\begin{array}{l}\text { Married (ref. = single, divorced or } \\
\text { widowed) }\end{array}$ & $-0.428(0.417)$ & $0.156(0.302)$ & $0.353 * * *(0.129)$ & $-0.110(0.309)$ \\
\hline Local hukou (ref: non-local hukou) & $-0.090(0.378)$ & $1.290 * * *(0.264)$ & $0.262 * * *(0.113)$ & $1.414 * * *(0.270)$ \\
\hline Employed (ref: unemployed) & $-0.786 *(0.447)$ & $-0.261(0.323)$ & $-0.089(0.138)$ & $-0.521(0.330)$ \\
\hline \multicolumn{5}{|l|}{ With medical insurance (ref: without } \\
\hline medical insurance) & $-0.575(0.494)$ & $1.178^{* * *}(0.344)$ & $0.335 * *(0.147)$ & $1.726 * * *(0.351)$ \\
\hline \multicolumn{5}{|l|}{ Logarithm of annual household } \\
\hline income per household member & $0.025(0.189)$ & $0.093(0.129)$ & $-0.276 * * *(0.055)$ & $-0.423 * * *(0.132)$ \\
\hline RMSEA & \multicolumn{4}{|c|}{0.039} \\
\hline CFI & \multicolumn{4}{|c|}{0.881} \\
\hline
\end{tabular}

Notes: 1$) * p<0.1, * * p<0.05, * * * p<0.01$

2) A higher total score of GHQ suggests a worse mental health status

3) The sensitivity analysis applied the street view greenness (blueness) exposure within an 
alternative buffer area (i.e., 1,000 meter).

Table 7. Sensitivity check: The association between GlobeLand30 greenness (blueness) exposure and mental health.

Variable
Model 4

\begin{tabular}{llll}
\hline GHQ & $\begin{array}{l}\text { Neighbourhood } \\
\text { attachment }\end{array}$ & $\begin{array}{l}\text { Neighbourly } \\
\text { interaction }\end{array}$ & $\begin{array}{l}\text { Community } \\
\text { participation }\end{array}$
\end{tabular}

Estimate (S.E.) Estimate (S.E.) $\quad$ Estimate (S.E.) $\quad$ Estimate (S.E.)

Independent variables

GlobeLand30greenness

GlobeLand30 blueness

Neighbourhood attachment

Neighbourly interaction

Neighbourhood participation

Controlled variables

Male (ref: female)

Age

Education (ref: primary school or less)

High school

College or more

Married (ref. $=$ single, divorced or

widowed)

Local hukou (ref: non-local hukou)

Employed (ref: unemployed)

With medical insurance (ref: without medical insurance)

Logarithm of annual household income per household member

$$
\begin{aligned}
& -2.969 * * *(1.157) 1.481(1.517) \\
& -5.306 *(2.823) \quad 0.829(1.691) \\
& -0.228 * * *(0.044) \\
& -0.136(0.103) \\
& -0.164 * * *(0.043)
\end{aligned}
$$

$$
\begin{array}{llll}
-0.218(0.300) & -0.331(0.223) & -0.207 * *(0.093) & -0.257(0.223) \\
0.022(0.018) & 0.032 * *(0.013) & 0.022 * * *(0.005) & 0.049 * * *(0.013)
\end{array}
$$


RMSEA

0.037

CFI

0.905

Notes: 1$) * p<0.1, * * p<0.05, * * * p<0.01$

2) A higher total score of GHQ suggests a worse mental health status

3) The sensitivity analysis applied the GlobeLand30 greenness (blueness) exposure within an alternative buffer area (i.e., 1,000 meter). 